Journal of English Language Teaching and Applied Linguistics

ISSN: 2707-756X

DOI: $10.32996 /$ jeltal

Journal Homepage: www.al-kindipublisher.com/index.php/jeltal

\title{
Methodology Section of Graduate School Thesis Manuscripts: A Genre Analysis Probe of Rhetorical Structure
}

\author{
Honee J. Mosquera, MALTE ${ }^{1} \mathbf{8}$ (D) and Donnie M. Tulud, Ph.D. ${ }^{2} \mathbf{8}(\mathrm{D})$ \\ ${ }^{7}$ Department of Education, University of Southern Mindanao-Graduate School, Makilala, Cotabato, Philippines \\ ${ }^{2}$ University of Southern Mindanao-Graduate School and Department of English Language and Literature, Kabacan, Cotabato, \\ Philippines
}

$\triangle$ Corresponding Author: Donnie M. Tulud, E-mail: dmtulud@usm.edu.ph

\section{ARTICLE INFORMATION}

Received: July 14, 2021

Accepted: August 20, 2021

Volume: 3

Issue: 9

DOI: $10.32996 /$ jeltal.2021.3.9.4

\section{KEYWORDS}

Thesis Manuscripts, Genre analysis, Methodology Section, Rhetorical Structure

\section{ABSTRACT}

The methodology section of thesis manuscripts is one of the important parts that should be well written. From this premise, a genre analysis was conducted to 30 Master of Arts in Language Teaching (MALT-English) research articles of the Graduate School in University of Southern Mindanao (USM). The study aimed to determine the rhetorical move structure and the moves that dominate in the methodology section of the said research articles. Results revealed that the methodology section has 5 moves with corresponding steps. These include Move 1: Introducing the Method chapter; Move 2: Presenting the Design of the Study; Move 3: Describing data collection method; Move 4: Clarifying Data Analysis Procedure; and Move 5. Establishing the ethical considerations and trustworthiness of the study. Obligatory steps identified are Pointing out the research design used in the study under Move 2, Presenting the Design of the Study; Describing the locale, participants/respondents and data source/research materials and research instrument/s; and Describing methods and steps in data collection under move 3, data collection method. While the moves are similar in 30 articles, there are steps which are interchanged and are either evident or not evident in some articles. This implied that writers employ varied steps in writing the methodology section even if they are of similar discipline.

\section{Introduction}

The methodology is a general term to cover whatever researchers decide to include in the chapter, where the authors discuss alternative methodological approaches, justify the chosen research method, and describe the process and participants in your study (Lynch, 2014). Writing a research paper is a dilemma especially for those who are not acquainted with the contents of a scientific paper. The methodology section of the research is one of the important parts that should be well written. However, Manchishi, Ndhlovu and Mwanza (2015) found out in their study that failure in writing the methodology is one of the problems of students in writing their research papers. Kikula and Quorro (2007); Kombo and Tromp (2011) also observed that in most research papers they have studied, the methodology is not formed well. Tulud (2016) in his study on the rhetorical moves of research articles also concluded that "the occurrence of steps in each article is somewhat incoherent within each discipline in which there are also writers who do not use some steps in introducing a certain move".

Furthermore, Dueñas (2007) claimed that less attention is given to the methodology section; and there is still no clear model for the communicative functions of this section in research articles (RA) in all disciplines, as claimed by Kanoksilapatham (2005). Tulud (2016) also studied the methodology section of research articles of the three flagship research journals published by the University of Southern Mindanao. But as indicated by Peacock (2011), as genre conventions vary across disciplines, non-native English writers need to know the move structure of Method sections in their own disciplines.

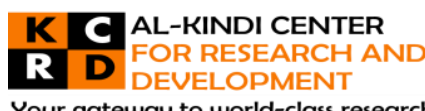

Your gateway to world-class research

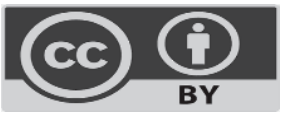

Published by Al-Kindi Center for Research and Development, United Kingdom. Copyright (c) the author(s). This open access article is distributed under a Creative Commons Attribution (CC-BY) 4.0 license 
With such premise, it raises concers on how then the methodology, an important section of the research paper, be formed and written coherently? This calls for a thorough study on how the approved researches in graduate school are written. Hence, genre analysis is necessary. Genre analysis facilitates this understanding among readers of these researches. Genre analysis is about understanding how a text is structured and it has influenced several researchers to explore texts of different genres to gain insights into the flow of texts, their moves, and patterns (Swales, 1990). Realizing the need to understand of a certain text like the methodology sections of the scientific papers, this study deals with move structure analysis of the methodology section of the graduate school studies.

\subsection{Purpose}

The purpose of this qualitative study employing Genre Analysis was to explore the moves employed in the methodology section of the graduate school studies in the University of Southern Mindanao, Kabacan, Philippines. It also specifically determined what moves are considered dominant in the said section.

\subsection{Research Questions}

1. What is the rhetorical move in the methodology section of the graduate school studies?

2. What types of moves dominate in the methodology section of graduate school studies?

\subsection{Theoretical Framework}

Since the researcher dealt with corpora taken from the methodology section of graduate school researches written by those who study MALT (English), the study made use of the analytical framework of Chen and Kuo (2012) for analyzing the Method chapters in Applied Linguistics. They proposed a 5-move model and these moves include: Move 1: Introducing the Method chapter; Move 2: Describing data collection method and procedure(s); Move 3: Delineating methods of data analysis; Move 4: Elucidating data analysis procedure(s); and Move 5: Referring to other studies.

Each move has corresponding steps. Move 1, introducing the method chapter, includes steps such as Indicating chapter/section structure; providing an overview of the study; and indicating theory/approach. Move 2, describing the sample (participants, location, time, etc.); describing methods and steps in data collection; and justifying data collection procedure(s). Move 3, presenting an overview of the (data analysis) design; explaining a specific method(s) of data analysis; explaining variables and variable measurement; justifying the methods of measuring variables or data analysis. Move 4, Relating (or recounting) data procedure(s); justifying the data analysis procedure(s); and previewing results. For Move 5, steps are providing background information; providing definition of terms; and providing support or justification.

\section{Literature Review}

\subsection{The Methodology Section of the Research Papers}

The methods section is the most important aspect of a research paper because it provides the information by which the validity of a study is ultimately judged. Therefore, the author must provide a clear and precise description of how the research was done, and the rationale for the specific research procedures chosen. It must be written with enough information so that: the research could be repeated by others to evaluate whether the results are reproducible, and the audience can judge whether the results and conclusions are valid (Kallet, 2004).

As pointed out by Azevedo et al. (2011), the methodology section should be written in a clear and concise manner, but should always present enough information so that: (1) the study could be replicated by other researchers, in order to evaluate the reproducibility of results (it should not be a step-by-step tutorial but should be a systematic and complete description of what was done), and (2) the readers are able to judge the validity of results and conclusions presented.

The methods section should ideally be structured in a set of subsections describing its main content. A possible structure is proposed along this paper including the following subsections according to Branson (2004); Kallet (2004), are the Study design; Selection of participants - selection criteria and selection methods; Data collection - variables, methods and instruments; and Data analysis. Each one of these subsections could have additional subheadings as appropriate.

\subsection{Genre Analysis}

Genre analysis is an approach used to study the relationship between a particular type of text and its context by dividing the text into small semantic units called moves. Each move has different communicative purposes that are shared among community members and this is reflected by the language use to serve specific functions. The combination of moves reveals structural patterns of the rhetorical discourse, and their sequence based on the author's communicative goals. 
The central tenet of Swales (1990) on genre analysis points out that "a genre comprises a class of communicative events, the members of which share some set of communicative purposes". A particular type of text can be divided into small semantic units called moves. Each move has different communicative purposes that are shared among community members and this is reflected by the language use to serve specific functions. The combination of moves reveals structural patterns of the rhetorical discourse, and their sequence based on the author's communicative goals (Swales, 1990).

To gain insight into the text and its constituents, the way it is composed, interpreted and used, Swales employed genre analysis of the introduction section of each research article. From his study, he proposed the model Create a Research Space (CARS). Swales' research introduced how a text is structured and it has influenced several researchers to explore texts of different genres to gain insights into the flow of texts, their moves, and patterns. The model has been applied in several studies on parts of scientific journal research reports, for example, abstracts.

Swales' model of genre analysis, move structure analysis, classifies segments of texts according to their prototypical communicative purpose for a particular genre. In this respect, his model has been used as a framework in ESP research that focuses on the analysis and teaching of the spoken and written language required of non-native speakers in academic and professional settings (Hyon, 1996).

Similarly, for Bhatia (1991), genre analysis as an analytical framework which reveals not only the utilizable form-function correlations but also contributes significantly to our understanding of the cognitive structuring of information in specific areas of language use, which may help the ESP practitioners to devise appropriate activities potentially significant for the achievement of desired communicative outcomes in specialized academic or occupation areas. In this sense, genre analysis does not have only pedagogical potential but can also illuminate the process of communication in a given genre. Genre analysis thus combines grammatical insights with corresponding socio-cognitive and cultural explanations. It aims at explaining language in use rather than linguistic forms on the surface level (Bhatia 2001).

Swales (1990) argues that texts are divided into units or "moves" depending on the communicative purpose each unit serves. A move is defined as "a discoursal or rhetorical unit that performs a coherent communicative function in a written or spoken discourse" (Swales, 2004, p. 228). Swales also adds that a move in the ESP genre analysis is identified by recognizing the functional role of the move in a text. The identification of a move does not only involve the boundaries of a sentence or a paragraph. Each move may consist of several sentences or paragraphs, which, considered together, serve a specific communicative purpose. The sub purposes of the moves ultimately shape the overall communicative purpose and the rhetorical structure of the genre (Bawarshi \& Reiff, 2010; Bhatia, 1993; Kanoksilapatham, 2005; Parodi, 2014; Sadeghi \& Samuel, 2013). The distinctive organization of the moves in texts belonging to one genre is "what provides its identity and distinguishes it from other genres" (Parodi, 2014).

For example, Swales (1990) examined research article introductions by applying the rhetorical move-analysis framework. The analysis resulted in what is now known as the Create a Research Space (CARS) model, the model that describes the moves that can occur in research article introductions, that is, their rhetorical genre structure. The model also identifies the steps within moves (i.e., options the writers use in a genre to achieve the communicative purpose of a move) found in research article introductions. After moves and steps in a genre have been identified based on their function (i.e., communicative purpose), the analysis is usually complemented by an investigation of some linguistic realizations of the genre purpose(s). These include the linguistic features that characterize moves such as the use of tenses, verbs, voice, or pronouns. The purpose of such integration of move/step analysis and lexico-grammatical analysis is to capture how moves are linguistically constructed in texts belonging to the same genre (Joseph et al., 2014).

In the CARS model (Swales, 1990), typical moves in the research article introductions were first identified based on the communicative purpose of each move. These moves include: "establishing a territory" (move 1), "establishing a niche" (move 2), and "occupying the niche" (move 3). Within the identified moves, Swales distinguishes the steps that build the moves such as, for example, the "indicating a gap" step or the "adding to what is known" step in move 2. Further analysis of lexico-grammatical features was conducted by investigating different features, such as the frequency of reporting verbs (e.g., show, claim). Swales also examined how authors of research article introductions use different citation formats and the reasons why they choose a specific format over the other.

Swales' (1990) research introduced how a text is structured and it has influenced several researchers to explore texts of different genres to gain insights into the flow of texts, their moves, and patterns. The model has been applied in several studies on parts of scientific journal research reports, for example, abstracts (Kenneth \& Maclean,1997; Tseng, 2011), introductions (Joseph, Lim, 
\& Nor, 2014; Swales, 1990), results and discussion (Amnuai \& Wannaruk, 2012; Ruying \& Allison, 2003); and full scientific journal research reports (Kanoksilapatham, 2005; Tseng, 2011).

Anthony (1999) investigated how CARS can be appropriately used to understand the structure of the introductions in software engineering articles. As a result, there are three steps in the model to be modified to fit in the 12 corpora being used in the study. In particular, there are steps which are found redundant; there are definitions in the introduction which are not mentioned in CARS; and there are evaluations as to practicality and novelty of the study (named as evaluation of research and included in Move 3-Occupying the Niche).

In the study of Samraj (2002) using the introductions of Wildlife Behavior and Conservation Biology, CARS model was also adapted. The findings showed that Reviewing items of previous research (Step 1-3 in CARS) does not occur just in the first move, but can be embedded within other steps, such as gap-indicating (Move 2) or goal specification (Move 3). Hence, Samraj suggests to remove the Reviewing items of previous research (Move 1), and have it as "free-standing sub-step" which can be embedded in any steps of the introduction.

Research articles, as a means of communicating and transmitting new knowledge, are widely used texts for rhetorical genre analysis (Hyland 2004). Nevertheless, a discourse community essentially engages in a plurality of genres (Bhatia 2002), and considering texts beyond the research article is significant to the discovery the of practices and values of the discourse community.

Move analysis is one example of a top-down approach (Biber, Connor, \& Upton, 2007; Pho, 2008) of genre analysis. A top-down approach is an analytical approach in which moves are assigned first on the basis of the content, meaning, and function of the parts in a text. Then, linguistic realizations are examined in the identified moves, as explained above. This analytical approach is different from a bottom-up analysis (Biber et al., 2007; Pho, 2008) which refers to identifying segments of texts based on specific linguistic clues such as using to sum up to indicate the goal of providing a conclusion in, for example, a research article. The linguistically identified segments are grouped together, and then the communicative purpose of the linguistically similar segments is determined. What differentiates these two analytical approaches is the role of the communicative purpose or the function each segment serves in a text. In a top-down approach, the communicative purpose is the first step while in a bottomup approach, the function of the linguistic segments is determined as a final step in the analysis (Biber et al., 2007).

In analyzing unfamiliar genres, Bhatia (1993) further developed the genre analysis approach initially proposed by Swales (1990) and extended its application to language use in professional settings. While Swales uses the term "steps" to refer to the building blocks of a move, Bhatia labels them as "different rhetorical strategies". Bhatia (1993) outlined a seven-stage practical process used to conduct ESP genre analysis, which this research study adopts to complement the Swalesian genre analysis approach discussed above. The stages involve:

1. "Placing the given genre-text in a situational context", where the situational context includes past experience and discipline knowledge which the researcher acquires from being part of the community the genre belongs to. If the researcher is not a part of that community, it is suggested that knowledge and experience can be obtained from surveying the literature related to the genre; 2. "Surveying existing literature", which includes many resources such as theories of genre analysis, methods, history of the community that uses the genre, and looking at related genres; 3. "Refining situational/contextual analysis" by identifying the speaker/writer of the text in question, audience, the community, other related texts, and examining the relationships of all these combined; 4. "Selecting corpus" by establishing the communicative purpose(s) and the context; 5 . "Studying the institutional context" by examining the conventions and rules of language use. These rules can be explicitly or implicitly stated and can be found in manuals, guide books, and literature available, depending on the context of the investigated genre; 6 . "Levels of linguistic analysis" by conducting one or more of the levels of linguistic analysis. These levels include the analyses of lexicogrammatical features such as tenses and clauses, text-patterning or textualization, which explains the purpose of a particular linguistic feature in a text, and structural organization of the text-genre, which includes assigning moves according to the specific communicative function they serve in a text. The communicative purpose of each move is "always subservient to the overall communicative purpose of the genre"; and 7. "Specialist information in genre analysis", which can be obtained by consulting another analyst and/or a user of the genre (an informant) to check the findings. This will add validity to the findings, as well as add an informant's perceptions to the analysis.

Using genre analysis to analyze an academic text can be through micro and macro levels of which in the micro-level, the researchers scrutinize how grammar or lexis are used in writing, like how modalities, hedging, and reporting verbs are employed (Salager-Meyer 1992; Hyland 1996), metadiscourse markers (Hyland 2000), and lexical verbs (Williams 1996). 
On the other hand, at the macro level, especially within the English for Specific Purposes (ESP) tradition, researchers deal with the patterns of rhetorical organizations of academic texts in various disciplines. The rhetorical organization of a text is often described as being made up of series of rhetorical "moves", defined as a segment of text that is shaped and constrained by a specific communicative function (Holmes 1997). Therefore, when a stretch of text is identified as containing a coherent rhetorical function, it will be analyzed as a move whose labeling unambiguously indicates its function. Within each move there are one or more further realizations known as "steps" or "strategies". These functional components (moves, steps or strategies) can be identified for each genre and such knowledge (presence, absence, and sequence of components) can then be used in the context of ESP instruction.

\subsection{Related Studies on the Move Structure of the Methodology Section of the Research Papers}

Lim (2006) analyzed twenty RA Method sections from two high-status management journals and found that most Method sections in his corpus contained three major moves: describing data procedures, delineating procedures for measuring variables, and elucidating data analysis procedures. Moreover, there were differences between each rhetorical move and the linguistic features in the constituent steps of each move.

In a study conducted by Dueñas (2007), who analyzed 24 business management Method sections of the two corpora (English and Spanish), some marked differences between the two corpora were revealed. The range and number of steps (corresponding to the same move) included in the Spanish RA Method sections were less homogenous than those in the counterpart. Reference to the past research, Reference to previous literature, and Claiming validity predominantly occurred in the English corpus while they were infrequently found in the Spanish corpus. Dueñas (2007) believes that the differences may be the result of influences from the socio-cultural contexts where the RAs were written and published.

Another study focusing on the Method section across eight disciplines is by Peacock (2011) and seven moves and the interdisciplinary differences in relation to rhetorical moves and move cycles were found in his large corpus (288 RA Method sections).Procedure occurred in all the Method sections. While Materials and Analysis moves were extremely common in the hard sciences (Biology, Chemistry, and Physics), Subjects and Data analysis were the salient moves in the soft sciences (Business, Language and Linguistics, Law, Public and Social Administration).

In terms of moves and steps of the methodology section, a five-move model by Chen and Kuo (2012) for analyzing the Method chapters in Applied Linguistics is presented below:

\begin{tabular}{|l|l|}
\hline \multicolumn{1}{|c|}{ Moves } & \multicolumn{1}{c|}{ Steps } \\
\hline Move 1: Introducing the Method chapter & $\begin{array}{l}\text { - Indicating chapter/section structure } \\
\text { - Providing an overview of the study } \\
\text { - Indicating theory/approach }\end{array}$ \\
\hline $\begin{array}{l}\text { Move 2: Describing data collection method and } \\
\text { procedure(s) }\end{array}$ & $\begin{array}{l}\text { - Describing the sample (participants, location, } \\
\text { time, etc.) } \\
\text { - Describing methods and steps in data collection } \\
\text { - Justifying data collection procedure(s) }\end{array}$ \\
\hline Move 3: Delineating methods of data analysis & $\begin{array}{l}\text { - Presenting an overview of the (data analysis) } \\
\text { design } \\
\text { - Explaining specific method(s) of data analysis } \\
\text { - Explaining variables and variable measurement } \\
\text { - Justifying the methods of measuring variables or } \\
\text { data analysis }\end{array}$ \\
\hline Move 4: Elucidating data analysis procedure(s) & $\begin{array}{l}\text { - Relating(or recounting) data procedure(s) } \\
\text { - Justifying the data analysis procedure(s) } \\
\text { - Previewing results }\end{array}$ \\
\hline Move 5: Referring to other studies & $\begin{array}{l}\text { - Providing background information } \\
\text { - Providing definition of terms } \\
\text { - Providing support or justification }\end{array}$ \\
\hline
\end{tabular}

Chen and Kuo's (2012) framework for the method chapter of M.A. theses in Applied Linguistics is also applied by Nguyen and Pramoolsook (2015) in the method chapters written by Vietnamese TESOL master's students in Applied Linguistics from ProQuest Dissertations and Theses database. The results showed both the differences and the commonalities shared by these two groups of writers. The findings revealed that both Method chapter corpora had five moves and a linear pattern of the 
first four moves in which the independent move of Referring to other studies was found to function as support and justification. Moreover, Moves 1 and 2 were obligatory while Moves 3 and 4 were conventional and optional, respectively. In terms of steps, Indicating chapter/section introduction and Describing samples were found in all Method chapters and Previewing results was completely absent. While the commonalities with regard to the move step structures of the Method chapters of these two thesis corpora reflect these Vietnamese writers' compliance to the international norms, the variations are likely to indicate their adaptation to the expected practice of composing these chapters in their local discourse comm '.. - - - nresence of Move 1 , the newly identified move of Chapter summary with two conventional steps (Summarizing th chapter content) and the high frequent cycle of Instrument-Purposes-Justificatic oducing the next each research instrument/method tend to indicate the expected convention.

\section{Methodology}

\subsection{Research Design}

In this research, textual analysis specifically, genre analysis was utilized. There are many types of textual analyses. For Zhou and Sloan (2009), textual approaches could be discourse analysis, narrative analysis, rhetorical analysis, auteur analysis, and generic analysis. The latter will be used for this study. Zhou and Sloan (2009) refer to genre analysis as "generic analysis" and classify it as a critical and cultural studies research method.

In Swales' genre analysis, the structural organization of a text is examined by identifying information units called moves, each of which is designed to achieve one main communicative purpose, and assessing how these moves are organized within the text to achieve the overall communicative purposes of a given genre (Swales \& Feak 2000). The understanding of the communicative purpose of the target genre and its social context (including the writer-reader relations, history of their interaction, and the cultural background) thus becomes essential for a comprehensive genre analysis (Bhatia, 1993; Dudley-Evens, 1994; Yasuda, 2011).

In this study, genre analysis was used since this aimed to understand the structure of the methodology section of the graduate school researches. It specifically delineated the steps involved in writing the methodology section in order to materialize each move and step in the texts.

Furthermore, the presentation of the data for this study was quantitative in nature as it accounted the frequency of how the moves and steps appear in the data being analyzed. However, the descriptions of the moves and steps were qualitative in nature as the analysis also dealt with qualitative data.

\subsection{Research Materials}

The research materials were the 30 copies of the methodology section of the graduate school researches. These were photocopied from the hardbound theses submitted to the school library. The theses were authored by the MA in Language Teaching (MALT) major in English graduates from the year 2015 to 2018. The selection was done randomly until 30 copies were gathered.

\subsection{Data Source}

The source of the research materials being utilized in the study were the Graduate School Theses of MA in Language Teaching (MALT) of the University of Southern Mindanao (USM). The school librarian gave the permission to the researcher to produce copies of these theses' methodology sections to be used in the study.

Part of the inclusion criteria for the selection of materials was the year the thesis was submitted to the library for compilation, of which it should be from 2015 to 2018; it should be a completed research and is authored by a MALT graduate student. Excluded were those theses written in the year 2015-2018 by a non-MALT student.

\subsection{Data Collection Procedures}

Prior to the conduct of the study, the researcher asked permission from the Dean of the Graduate School to allow the researcher to secure copies of the methodology section of the selected graduate school researches. When the permission was obtained, the researcher proceeded to the graduate school library for the selection of researches where the methodology sections were used as corpora of the study.

When the researches to be used in the study were identified, the researcher photocopied the methodology sections of the books. These photocopied methodology sections were used as research materials. Copies were used for the genre analysis. These were stored for validation and audit trail purposes. 


\subsection{Data Analysis}

The researcher prepared the copies of the 30 methodology sections taken from graduate school researches. Then the researcher read and re-read the corpora to understand the rhetorical situation of the genre. This is important for the researcher to understand the context of the text being analyzed.

The corpora were first analyzed for their overall organization by looking at the section headings. The section headings within these chapters were noted and compared because they indicate the function of the section and $\mathrm{m}$ moves and steps in the chapter. This were followed by a detailed investigation in terms of $\mathrm{m}$

vo an indication of the model by Chen and Kuo (2012).

\section{Results and Discussions}

\subsection{Move Structure in the Methodology Section of Graduate Studies}

With the use of the analytical framework, the five-move model by Chen and Kuo (2012), the methodology section of the graduate studies was analyzed. The corpora were 30 methodology sections of the graduate school theses of MALT students.

Table 1 reveals the move structure and the corresponding steps in the methodology section. The paper was divided into 5 moves with corresponding steps. The moves are not based on subheadings alone but also on the sequence of how these parts of the paper being described below appear.

\section{Move 1: Introducing the Method Chapter}

Step 1: Indicating the chapter or the section structure

This move constitutes only one step - Indicating the chapter or the section structure. This is the part where the researcher tells the readers what the chapter is all about and what elements of the methodology can be specifically read on it.

This chapter presents the research design, locale of the study, respondents of the study, sampling technique used, research instrument, data-gathering procedure, and the methods utilized in the analysis of the data for the study. RAM1

This section contains the method used in the conduct of the study. It introduces the research design, role of the researcher, research locale, research participants and key informants, data collection procedure and analysis, data source and validation of findings. RAM7

Table 1. The Move Structure of the Methodology Section of the Graduate School Studies

\begin{tabular}{|c|c|}
\hline Moves & Steps \\
\hline $\begin{array}{l}\text { Move 1: Introducing the Method } \\
\text { chapter }\end{array}$ & 1.1 Indicating the chapter/Section Structure \\
\hline $\begin{array}{l}\text { Move 2: Presenting the Design of } \\
\text { the Study }\end{array}$ & $\begin{array}{l}\text { 4.1 Pointing out the research design used in the study } \\
\text { 4.2 Explaining why the design is appropriate for the study } \\
4.3 \text { Citing authorities to back up the decision to use the design }\end{array}$ \\
\hline $\begin{array}{l}\text { Move 3: Describing data } \\
\text { collection method }\end{array}$ & $\begin{array}{l}\text { 3.1. Pointing out the researcher's role in research } \\
\text { 3.2 Describing the locale, participants/respondents and data } \\
\text { source/research materials and research instrument/s } \\
\text { 3.3. Describing methods and steps in data collection }\end{array}$ \\
\hline
\end{tabular}




\begin{tabular}{|c|c|}
\hline $\begin{array}{l}\text { Move 4: Clarifying Data Analysis } \\
\text { Procedure }\end{array}$ & $\begin{array}{l}\text { 4.1 Describing the method of analysis } \\
\text { 4.2 Pointing out the steps in data analysis } \\
\text { 4.3 Justifying the steps employed in data analysis }\end{array}$ \\
\hline $\begin{array}{l}\text { Move 5. Establishing the ethical } \\
\text { considerations } \\
\text { trustworthiness of the study }\end{array}$ & $\begin{array}{l}\text { 5.1 Stating the overview of ethical procedures employed } \\
\text { 5.2. Describing the steps in ensuring ethical conduct of research } \\
\text { 5.3 Stating the overview of the trustworthiness criteria in conducting } \\
\text { research } \\
5.4 \text { Citing authorities describing the criteria of ensuring } \\
\text { trustworthiness } \\
\text { 5.5 Describing the steps involved in ensuring the trustworthiness of } \\
\text { the study }\end{array}$ \\
\hline
\end{tabular}

\section{Move 2. Presenting the Design of the Study}

Step 2.1. Pointing out the research design used in the study. This step under the presentation of the design is the part of the methodology section which directly specifies what design is being employed in the study and the brief description of what the design. This is how it appears:

The researcher used true experimental design. Gibbons (1997) cited that this category of design includes more than one purposively created group common measured outcomes. RAM11

Qualitative research design was used in this research employing content analysis. Qualitative research is a process of naturalistic inquiry. It does not focus on the outcome or product (Creswell, 1994). RAM15

Step 2.2 Explaining why the design is appropriate for the study. After the research design is being pointed out, the researcher proceeds to presenting reason or reasons why the design is fitted for the study.

Since this qualitative-narratology study aimed to scrutinize, describe, analyze, and interpret the detailed experiences, the strategies employed during interventions and the insights gained in handling learners with learning difficulties, the above-mentioned approach was considered appropriate. RAM19

Qualitative phenomenological study describes the meaning for several individuals' lived experiences of a concept or a phenomenon. Hence, this research focused on describing what all participants have in common as they experience the given phenomenon of the study where non- English major teachers teaching English. RAM13

Step 2.3 Citing authorities to back up the decision to use the design. After presenting the reason why the design is chosen, some writers also cite authorities to support their reasons why the design is appropriate for their study.

McKee (2003) defined textual analysis as a way for researchers to gather information about how human beings make sense of the world. It is a methodology-a data gathering process- for those researchers who want to understand the ways in which member of each culture and subcultures make sense of what they are, and how they fit into the world in which they live in. RAM23

Exploring can include activities such as providing information, giving reasons or making causal statement 9Bogdan \& Bikken, 1998; Patton, 1990; Yin, 1994). This study aims to explore the bones and banes of non-English major teachers in teaching English subject.RAM29 


\section{Move 3: Describing data collection method}

3. 1. Pointing out the researcher's role in research. In describing the data collection method, researchers' first step is pointing out the role of the researcher.

It was the role of the researcher of this study to collect and analyze the data. The researcher interviewed 15 teachers from selected elementary school...then the data was transcribed and analyzed by the researcher. RAM12

In this phenomenological research, the researcher served as the main instrument of the study. The researcher was responsible in gathering all the data vital for the completion of the study.RAM13

3.2 Describing the locale, participants/respondents and data source/research materials and research instrument/s. The move also consists of the steps of describing the locale, participants and data source or materials of the study as well as the research instrument like the interview guide questions and the survey questionnaire being used in data collection.

The study was conducted at Libungan National High School. \{...\} The respondents of the study were the 238 Grade seven students. \{...\} The research instrument used was a standardized reading material from Suggested Reading Laboratory. RAM2

Twelve Grade 3 teachers from three pilot schools in Carmen were chosen by the researcher as respondents based on the inclusion criteria set for the study. A semi-structed in-depth interview was used as data gathering tool. RAM6

3.3. Describing methods and steps in data collection. This is another step under Move 3 . The researcher describes how data collection is done.

The data needed in this research were gathered through comprehensive examination of application letters and in-depth interview conducted among 13 participants. Permission was sought... \{...\} Initial inquiry with the Director of HRMDO was made to confirm job application letters... \{...\} In-depth interview was conducted...RAM8

...the researcher asked first the permission of the School Division Superintendent, District Supervisors and Principals of the selected elementary schools in Kabacan. After which, in-depth interview to the participants was conducted. Then, FGD was organized. RAM11

\section{Move 4: Clarifying Data Analysis Procedure}

Step 4.1 Describing the method of analysis. This step is employed in the methodology sections by giving definition or by describing the method of analysis being used. It directly names the analysis used and immediately followed with the description like where it was taken or who owns the framework of the analysis.

Coding styles of Rossman and Rallis (2012) and the thematic analysis of Creswell (2004) were employed. RAM25

The genre and corpus in this study was the research abstracts which were analyzed with the utilization of the rhetorical moves model proposed by Ken Hyland (2000) and Halliday's (1976) work of cohesion for linguistic features. RAM27

Step 4.2 Pointing out the steps in data analysis. The move on data analysis procedure also includes the steps which pointed out what has been done during the data analysis. The authors accounted the steps to facilitate the analysis until completion.

I recorded the answers from the interview and patiently translated. The categories were grouped and classified. The interpretations of the results were presented through a tabular presentation to illustrate the findings of the data. RAM29

The explicit ("said") themes were decoded and classified. Then the traces of the implicit ("unsaid") concepts were revealed based on the language used in the stories. Themes common to the stories were consolidated, compared and contrasted to the related literature. RAM4 
Step 4.3 Justifying the steps employed in data analysis. The authors also justify the steps that they used in the analysis by citing authors who suggested or proposed the steps in the analysis.

In data analysis, I employed the three steps according to the study of Gempes (2008). RAM29

Moves were anchored on the frame of yang and Allison (2030) for research conclusions while the cohesive devices were analyzed using Halliday and Hassan (1976). As expected, the obligatory and optional moves were identified.RAM16

Move 5. Establishing the ethical considerations and trustworthiness of the study. This move consists of 5 steps which are discussed below.

Step 5.1 Stating the overview of ethical procedures employed. This is the step where the researcher introduced in a sentence or two, the value of employing the ethical considerations and at the same time what particular considerations were employed.

Awareness of ethics behind a research activity is fundamental in an academic or professional setting. Ethical consideration can be clarified through the consultation of ethical guidelines of one's professional associations. RAM8

Since my research study involved people expected to be hesitant to disclose information our of fear and withheld some data, several safeguards were applied to erase their fears and promoted trust. I ensured that my study was guided by ethical principles...RAM28

Step 5.2. Describing the steps in ensuring ethical conduct of research. The steps on what the researcher have done to ensure that the conduct of research is ethical are also presented in the methodology.

All participants have the rights to withdraw their information anytime. After the interview, they will be given enough time to verify their transcripts so that the participants have a change to modify their information that may identify them or they are not comfortable on the future results of their transcripts. ... \{...\} All participants were given informed consent to be part of the research process and I explained to them the content of the consent. RAM29

The participation of the participants in the study was voluntary and their identifies were never disclosed. Informed consent was obtained prior to the conduct of the classroom interaction recordings. The transcribed interviews were coded to hide the identities of the participants. RAM20

Step 5.3 Stating the overview of the trustworthiness criteria in conducting research. Trustworthiness of the study is presented by giving first the overview of what are those elements in ensuring trustworthiness.

In this study, it is important to strictly follow the research design, research methodology and research procedures. The data collection plays an important part in findings the result of the research to produce a qualified study. Hence, this study utilized assessment of truth in a qualitative research; credibility, transferability and dependability. RAM6

The important factors in the methods of Lincoln and Guba (1985) on the assessment of truth in a qualitative report were credibility, conformability, dependability and transferability. These were obliged to evaluate the worth of the study. RAM12

Step 5.4 Citing authorities describing the criteria of ensuring trustworthiness. The researchers also cite authors who give descriptions of how trustworthiness is achieved and the criteria of ensuring trustworthiness.

Transferability seeks to determine if the results related to other contexts and be transferred to contexts (Lincoln \& Guba, 1985; Miles and Hiberman, 1994). RAM13

Ary, Jacobs and Razavieh (2002) accentuated that dependability is met my stabling an "audit trail". RAM20 
Step 5.5 Describing the steps involved in ensuring the trustworthiness of the study. The researcher after citing the authors regarding how the criteria of the trustworthiness can be achieved, also describe the steps on how these are ensured in their own study.

To ensure dependability, the procedures within the study were recorded in particulars for other future researchers to repeat the study and the reader to determine to which appropriate procedure will be followed...RAM21

To ensure credibility, the researcher made sure that the data source was credible. She personally did the recording of the classroom interaction. RAM25

\section{Moves that Dominate in the Methodology Section of the Graduate School Studies}

This study also accounted what particular moves and steps dominated in the Methodology section of the graduate school studies. Table 2 presents the findings of the study.

As shown in the table, the only step in Move 1 which is, indicating the chapter/section structure occurred in 22 corpora. This occupies the percentage of $73.33 \%$. This step is considered conventional among the papers of MALT graduates.

Move 2, presenting the design of the study where researchers point out what particular methodology is used as step one is an obligatory move showing that $100 \%$ of the studies employ this step. Steps 2 and 3 under this move are considered conventional moves since the percentage of occurrence in the corpora constitute $83.33 \%$ and $60 \%$ respectively (2.2 Explaining why the design is appropriate for the study; 2.3 Citing authorities to back up the decision to use the design).

Table 2. Moves that Dominate in the Methodology Section of the Graduate School Studies

\begin{tabular}{|c|c|c|c|}
\hline Moves & Steps & $\begin{array}{l}\text { Frequency of the } \\
\text { Occurrence }\end{array}$ & Percentage \\
\hline $\begin{array}{l}\text { Move 1: Introducing } \\
\text { the Method chapter }\end{array}$ & $\begin{array}{l}\text { Indicating the } \\
\text { chapter/Section Structure }\end{array}$ & 22 & 73.33 \\
\hline \multirow[t]{3}{*}{$\begin{array}{l}\text { Move 2: Presenting the } \\
\text { Design of the Study }\end{array}$} & $\begin{array}{l}\text { 2.1 Pointing out the research } \\
\text { design used in the study }\end{array}$ & 30 & 100 \\
\hline & $\begin{array}{l}2.2 \text { Explaining why the design is } \\
\text { appropriate for the study }\end{array}$ & 25 & 83.33 \\
\hline & $\begin{array}{l}2.3 \text { Citing authorities to back } \\
\text { up the decision to use the design }\end{array}$ & 18 & 60 \\
\hline \multirow[t]{3}{*}{$\begin{array}{l}\text { Move 3: Describing } \\
\text { data collection method }\end{array}$} & $\begin{array}{l}\text { 3.1. Pointing out the researcher's } \\
\text { role in research }\end{array}$ & 22 & 73.33 \\
\hline & $\begin{array}{l}3.2 \text { Describing the locale, } \\
\text { participants/respondents and data } \\
\text { source/research materials and } \\
\text { research instrument/s }\end{array}$ & 30 & 100 \\
\hline & $\begin{array}{l}\text { 3.3. Describing methods and steps } \\
\text { in data collection }\end{array}$ & 30 & 100 \\
\hline $\begin{array}{l}\text { Move 4: Clarifying Data } \\
\text { Analysis Procedure }\end{array}$ & $\begin{array}{l}4.1 \text { Describing the method of } \\
\text { analysis }\end{array}$ & 30 & 100 \\
\hline
\end{tabular}




\begin{tabular}{|c|c|c|c|}
\hline & $\begin{array}{l}4.2 \text { Pointing out the steps in data } \\
\text { analysis }\end{array}$ & 27 & 90 \\
\hline & $\begin{array}{l}4.3 \text { Justifying the steps employed in } \\
\text { data analysis }\end{array}$ & 16 & 53.33 \\
\hline \multirow{5}{*}{$\begin{array}{l}\text { Move 5. Establishing } \\
\text { the ethical } \\
\text { considerations and } \\
\text { trustworthiness of the } \\
\text { study }\end{array}$} & $\begin{array}{l}5.1 \text { Stating the overview of ethical } \\
\text { procedures employed }\end{array}$ & 13 & 43.33 \\
\hline & $\begin{array}{l}\text { 5.2. Describing the steps in } \\
\text { ensuring ethical conduct of } \\
\text { research }\end{array}$ & 17 & 56.67 \\
\hline & $\begin{array}{l}\text { 5.3 Stating the overview of the } \\
\text { trustworthiness criteria in } \\
\text { conducting research }\end{array}$ & 17 & 56.67 \\
\hline & $\begin{array}{l}5.4 \text { Citing authorities describing the } \\
\text { criteria of ensuring trustworthiness }\end{array}$ & 21 & 70 \\
\hline & $\begin{array}{l}\text { 5.5 Describing the steps involved in } \\
\text { ensuring the trustworthiness of the } \\
\text { study }\end{array}$ & 21 & 70 \\
\hline
\end{tabular}

Note: $\quad 0 \%-$ non-evident

$<60 \%$ - optional move

$>60 \%$ conventional move

$100 \%$ obligatory move

For Move 3: Describing data collection method, the first step devoted to pointing out the researcher's role in research is conventional with 22 occurrences among the 30 research methodology section (73.33\%); while the remaining two steps such as the Describing the locale, participants/respondents and data source/research materials and research instrument/s and Describing methods and steps in data collection are all obligatory. All of the methodology sections being analyzed exhibited these steps.

Furthermore, the data also showed that for Move 4, Clarifying Data Analysis Procedure, describing the method of analysis as initial step in materializing the step is considered obligatory as 30 out of 30 corpora employed this step. However, the steps which point out the steps (4.2) and justify the steps employed in data analysis (4.3) are conventional and optional moves in the methodology section.

Lastly, for Move 5, Establishing the ethical considerations and trustworthiness of the study, step 1 Stating the overview of ethical procedures employed is an optional move since occurrence is only 43.33\%(13 out of 30). Optional moves are also found in Steps 2, Describing the steps in ensuring ethical conduct of research and 3, Stating the overview of the trustworthiness criteria in conducting research.

Meanwhile, the step of giving the overview of the trustworthiness of the study is optional move; however, the succeeding steps: citing authorities describing the criteria of ensuring trustworthiness; and describing the steps involved in ensuring the trustworthiness of the study constituting steps 2 and 3 of Move 5 are considered conventional moves as they occurred in 21 research articles.

\section{Move Structure in the Methodology Section of Graduate Studies}

The move structure analysis was employed in the methodology section of the graduate studies particular those of the MALTEnglish. The results revealed that there are 5 moves in the methodology section and each move has corresponding steps. 
Move 1 is Introducing the Method Chapter, with the only step, Indicating the chapter or the section structure. This is the step where the researcher presents the parts included in the methodology section. Authors merely enumerate or list the items which readers can expectedly found in the said section. In the framework used, the five-move model by Chen and Kuo (2012), Move 1 has 3 steps however, there is only one step in the methodology section under study. In this move, the authors did not employ steps 2 and 3 of move 1 in the model. These steps are found in other moves.

The presentation of the design of the study which is part of Move 1 in the framework used is considered as the next move in the structure of MALT-English studies. This move constitute steps such as pointing out the research design used in the study (Step 1); Explaining why the design is appropriate for the study (step 2); and Citing authorities to back up the decision to use the design (step 3). These steps are not found in the framework of Chen and Kuo (2012) since the design of the study is considered in Move 1.

Moreover, labelled as Move 2 in the framework is considered Move 3 in the corpora. Move 3 is describing data collection method consists of steps such as Pointing out the researcher's role in research, Describing the locale, participants/respondents and data source/research materials and research instrument/s, and Describing methods and steps in data collection. Step 3 which is Describing methods and steps in data collection is labelled as the move in the framework of Chen and Kuo (2012); however, this is part of the steps in Move 3. Observably, the step identified in the framework particularly Justifying data collection procedure(s) is not found in the RA method sections of MALT-English papers.

Move 4 is Clarifying Data Analysis Procedure. This move is specifically devoted to how the researcher analyzed the data gathered. The steps here include Describing the method of analysis; Pointing out the steps in data analysis; and Justifying the steps employed in data analysis which was done by citing authors who suggested or proposed the steps in the analysis. Similarly, this move is classified also as Move 4 in the framework. However, the step, Previewing results is not found in the corpora.

For Chen and Kuo (2012), the last Move is Referring to other studies. But in the RA method section of MALT-English, the move is Establishing the ethical considerations and trustworthiness of the study. This move consists of 5 steps such as Stating the overview of ethical procedures employed; Describing the steps in ensuring ethical conduct of research; Stating the overview of the trustworthiness criteria in conducting research; Citing authorities describing the criteria of ensuring trustworthiness; and Describing the steps involved in ensuring the trustworthiness of the study. These steps are not found in any of the moves presented in the framework. In addition, this move structure is not also found in the analyses results of Nguyen and Pramoolsook (2015) who studied the method chapters written by Vietnamese TESOL master's students in Applied Linguistics; Lim (2006) who analyzed twenty RA Method sections from two high-status management journals; and Tulud (2016) who employed rhetorical move analysis of the methodology section of 27 research articles from the three flagship research journals of and published by the University of Southern Mindanao.

Results of the study further revealed that while moves across 30 RA methodology are the same, there are steps in each move which interchange. For instance, step 1 in Move 3 is found in step 2 or 3 in some RAs. The same findings are also generated by by Duenas (2002). The author noted the range and number of steps (corresponding to the same move) included in the Spanish RA Method sections were less homogenous than those in the counterpart. The same observation was also pointed out by Lim (2006) that there were differences between each rhetorical move in the constituent steps of each move.

It can be gleaned from the results of the study that every discipline has their own way of presenting the methodology section. But even in the study of Peacock (2011) from 288 RAMs across disciplines of which Language and Linguistics was one of the corpora, a seven-move scheme rhetorical organization involving seven major moves was established. These moves include the presentation of Subjects/Materials; Location; Procedure; Data Analysis; Limitations; Research aims/questions/hypotheses; and Overview. Some of these such as the limitations, research aims/questions/hypotheses and overview are not found in the RAs of MALT-English, a discipline which is related to what has been studied by Peacock.

Noticeably, reviews on studies focusing genre analysis of methodology section did not mention about the move 5 found in this study- Establishing the ethical considerations and trustworthiness of the study. The result of this study manifests that this move is important in ensuring the validity and reliability of the procedures employed in the study since majority of the corpora are qualitative designs where trustworthiness needs to be clarified.

The moves employed by the authors subscribe to the idea of pointed out by Azevedo et al. (2011) that the methodology section should always present enough information so the study could be replicated by other researchers, and the readers are able to judge the validity of results and conclusions presented. These are achieved in the methodology section since based on the moves present, reader will be able to evaluate the reproducibility of results with the presentation of the step-by-step procedure 
of conducting the research and complete description. Hence, readers may be able to assess the validity of the results based on the methods utilized.

\section{Moves that Dominate in the Methodology Section of the Graduate School Studies}

As far as elaborating the descriptions of obligatory, optional, and conventional moves utilized by the HIJ and NHIJ academic writers, Kanoksilapatham's (2011) proposal was adopted underscoring that a move is considered obligatory if it achieves $100 \%$ of occurrence; while an optional move is attained if it garners $60 \%$ to $99 \%$. Likewise, a move is considered conventional if it occurs $59 \%$ and below.

The steps in each move of the rhetorical structures of the methodology section of the graduate school studies are found obligatory and conventional and few of the moves or steps were considered as optional. Among the obligatory steps include Pointing out the research design used in the study under Move 2, Presenting the Design of the Study; Describing the locale, participants/respondents and data source/research materials and research instrument/s; and Describing methods and steps in data collection under move 3, data collection method; and Describing the method of analysis, the first step in Move 4, Clarifying Data Analysis Procedure. The findings is similar to Musa, Khamis, and Zanariah's (2015) who investigated 60 RAMs in the fields of medical and biomedical engineering retrieved from Scopus websites and found out that Describing procedures was found to be an obligatory move under the medical discipline.

Similarly, Kanoksilapatham (2011) developed a proposed model for biomedical engineering RA Methodology. The said schema involves three major moves with a number of steps under each move. It was found that Move 1, Stating procedures, was an obligatory move for it occurred $100 \%$ in the study corpus. Though when compared, MALT-English RAs do not have the same moves, this step is also evident and employed in obligatorily in move 4.

Morales (2016) also found that in the RAs from high-impact and non-high impact journals, there was one obligatory move (Move 1 Subjects/Materials) that both sets of academic writers employed. Gleaning from the results, RAs of the MALT-English as shown in the methodology section ensure that the descriptions of the research locale, participants/respondents and data source/research materials and research instrument/s; and the steps in data collection and method of analysis are presented for these are considered vital in the methodology.

Furthermore, there are also conventional moves and steps in the methodology section under study. These steps occurred $60 \%$ to $99 \%$ in the RAs. The steps which are found conventional are Indicating the chapter/Section Structure (Move 1); Explaining why the design is appropriate for the study (Move 2); Pointing out the researcher's role in research (Move 3); Pointing out the steps in data analysis (Move 4); and Citing authorities describing the criteria of ensuring trustworthiness, Describing the steps involved in ensuring the trustworthiness of the study (Move 5). These findings show similarities and differences to Peacock's (2011) study of which Move 3 (Delineating methods of data analysis), and Move 4 (Elucidating data analysis procedures); Chen and Kuo (2012); and Morales (2016) that Move 3 and Move 4 are conventional and optional, respectively. In this study, both are considered optional with $60 \%$ to $79 \%$ occurrences in RAs.

On the other hand, optional moves are found in Move 5 particularly the steps 5.1 Stating the overview of ethical procedures employed; 5.2. Describing the steps in ensuring ethical conduct of research; and 5.3 Stating the overview of the trustworthiness criteria in conducting research. It can be deduced from these results that RAs of the MALT-English subscribed to what Ary et al. (2007) and Lincoln and Guba (1985) have emphasized on qualitative research - trustworthiness of the study must be established.

\section{Conclusion}

Based on the overall results, it was revealed that the methodology section of thesis manuscripts in USM graduate school employ 5 moves with corresponding steps. These include Move 1: Introducing the Method chapter; Move 2: Presenting the Design of the Study; Move 3: Describing data collection method; Move 4: Clarifying Data Analysis Procedure; and Move 5. Establishing the ethical considerations and trustworthiness of the study. Obligatory steps identified are Pointing out the research design used in the study under Move 2, Presenting the Design of the Study; Describing the locale, participants/respondents and data source/research materials and research instrument/s; and Describing methods and steps in data collection under move 3, data collection method. The result based on the occurrence in each thesis manuscript indicates that while the moves are similar in 30 articles, there are steps which are interchanged and are either evident or not evident in some articles. This entails that writers employ varied steps in writing the methodology section even if they are of similar discipline. 


\subsection{Implication for Education Practice}

The use of genre analysis to an academic text like research articles prompted to various descriptions as to how each part are written in different disciplines. As revealed in the study, there are 5 moves employed in the graduate studies particularly those of the MALT-English. While the framework suggests 5 moves with corresponding steps, these some of these moves and steps are not present in the corpora. Conversely, there are also steps which are not found in the framework but are found in the rhetoric of these RAs. This implied that in MALT-English, there are specific rhetorical moves which are considered vital. Observably, most of these researches are qualitative in design. There are moves required in the qualitative research which are not found in quantitative researchers of other disciplines.

Research teachers of the graduate school may check on these moves and teach the same to graduate school students. The moves and steps when presented to the writer especially the beginning writers will enable them to clear out confusions as to what to write in the methodology knowing that they are always instructed to make the methodology section clear and concise with complete information as to how the research was done.

Another implication for education practice which can be derived from the study is that, research advisers and panel members may arrive at the consensus as to what Moves shall be required in the methodology section. Once this is clarified among the student researchers, it would be able for them to write the methodology appropriately based on the standards required of them. This would also mean uniformity as to the quality of the writing output particularly in the methodology section.

This study upholds the idea of Dudley-Evans (2000) who describes the CARS model as a leading key to enter a particular discourse community that requires its members to be informed with the writing conventions. Hence, in academic practice, genre analysis has vital contribution.

\subsection{Implication for Future Research}

From the findings of the study, future researches may be focused on how each of the steps can be realized. This means, researches may come up with the same study focusing on the linguistic elements employed or which can be employed by writers in presenting each move or steps in the methodology section since this study did not include determining the linguistic features. Finding out the linguistic features will also be helpful since these elements will guide the readers to have better understanding of the contents of the methodology; and at the same time guide writers on how these can be effectively used to make the section more understandable. For Crossley (2020), if writers understand what linguistic features and elements should be present in the text, they will also be able to write appropriately as to what content the text demands.

Moreover, researches employing genre analysis using other corpora can also be a room for research. There are other RAs in the graduate school of this University. These RAs might manifest other moves and steps not evident in this study. Conducting similar study using the same or other framework will help researchers gain deeper insights on how to effectively write this important section of the paper.

It is also suggested that the graduate school will specify the moves and steps required in the methodology section of certain discipline and find out which is obligatory and optional. These obligatory moves or steps may be required to students of the graduate school. From here, research may be conducted as to how effective requiring these moves is; and how do students feel being guided by such move. Doing so will supply the evidence of how rhetoric structure can help the students in writing their researches; and how this can improve the quality of the research articles of the Graduate School. Also, Afful, J.B.A., \& Kyei, E.(2020) suggested that another line of research may be directed from the standpoint that communicative purpose may be inadequate in unearthing fully the rhetorical disposition. As such, the register theory may be utilized to ascertain the lexico-grammatical resources by focusing on the ideational metafunction. 


\section{References}

[1] Afful, J.B.A., \& Kyei, E.(2020). Move Analysis of Letters of Recommendation Written by Lecturers in a Ghanian University. Journal of English Language Teaching and Applied Linguistics. 2(5),01-11. https://doi.org.10.32996/jeltal.2020.2.5.1

[2] Amnuai, W., \& Wannaruk, A. (2012). Investigating Move Structure of English Applied Linguistics Research Article Discussions Published in International and Thai Journals. English Language Teaching, 6(2), 1-13.

[3] Anthony, L. (1999). Writing research article introductions in software engineering: How accurate is a standard model?. IEEE transactions on Professional Communication, 42(1), 38-46.

[4] Ary, D., Jacobs, L. C., Irvine, C. K. S., \& Walker, D. (2018). Introduction to research in education. Cengage Learning.

[5] Azevedo, L. F., Canário-Almeida, F., Fonseca, J. A., Costa-Pereira, A., Winck, J. C., \& Hespanhol, V. (2011). How to write a scientific paperWriting the methods section. Revista portuguesa de pneumologia, 17(5), 232-238.

[6] Baxter, J., \& Eyles, J. (1997). Evaluating qualitative research in social geography: establishing 'rigour'in interview analysis. Transactions of the Institute of British geographers, 22(4), 505-525.

[7] Bhatia,V.K. (1993). Analyzing Genre: Language Use in Professional Settings. London: Longman.

[8] Bhatia, J.K. (2001). Worlds of Written Discourse: A Genre-based View. London: Continuum

[9] Biber, D., Upton, T., \& Connor, U. (2007). Discourse on the move: Using corpus analysis to describe discourse structure. Amsterdam: John Benjamins Publishing.

[10] Bitsch, V. (2005). Qualitative research: A grounded theory example and evaluation criteria. Journal of agribusiness, 23(345-2016-15096), 7591.

[11] Branson, R. D. (2004). Anatomy of a research paper. Respiratory Care, 49(10), 1222-1228.

[12] Chen, T. Y., \& Kuo, C. H. (2012). A genre-based analysis of the information structure of master's theses in applied linguistics. The Asian ESP Journal, 8(1), 24-52.

[13] Chilisa, B., \& Preece, J. (2005). Research methods for adult educators in Africa. Pearson Publishing.

[14] Crossley, S. (2020). Linguistic features in writing quality and development: An overview. Journal of Writing Research, 11(3).

[15] Dudley-Evans, T. (2000). Genre analysis: a key to a theory of ESP?. Ibérica, Revista de la Asociación Europea de Lenguas para Fines Específicos, (2), 3-11.

[16] Dueñas P. M. (2007). A cross-cultural analysis of the generic structure of Business Management Research Articles: The Method Section

[17] Holloway, l., \& Wheeler, S. (2002). Qualitative research in nursing. Wiley-Blackwell.

[18] Hyland, K. (1996). Writing without conviction? Hedging in science research articles. Applied linguistics, 17(4), 433-454.

[19] Hyland, K. (2000). Disciplinary Discourses: Social Interaction in Academic Writing. London: Pearson Education.

[20] Hyon, S. (1996). Genre in three traditions: Implications for ESL. TESOL quarterly, 30(4), 693-722.

[21] Joseph, R., Lim, J. M. H., \& Nor, N. A. M. (2014). Communicative moves in forestry research introductions: Implications for the design of learning materials. Procedia-Social and Behavioral Sciences, 134, 53-69.

[22] Kallet, R. H. (2004). How to write the methods section of a research paper. Respiratory care, 49(10), 1229-1232.

[23] Kanoksilapatham, B. (2005). Rhetorical structure of biochemistry research articles. English for specific purposes, 24(3), $269-292$.

[24] Kanoksilapatham B. (2011). Civil engineering research article introductions: Textual structure and linguistic characterization. Asian ESP Journal, 7(2), 55-84.

[25] Kenneth, A., \& Maclean, J. (1997). A genre analysis study of 80 medicalabstracts. Edinburgh Working Papers in Applied Linguistics, 8,123.

[26] Kikula, I. S. \& Quorro, M. A.S. (2007). Common Mistakes and Problens in Research Proposal Writing. Dar es Salaam: Research on Poverty Alleviation (REPOA).

[27] Kombo, D. K. and Tromp D. L. A (2011). Proposal and Thesis Writing. Nairobi: Paulines Publications Africa.

[28] Lincoln, YS., \& Guba, E.G. (1985). Naturalistic inquiry. Newbury Park, CA: Sage.

[29] Lim, J. M. H. (2006). Method sections of management research articles: A pedagogically motivated qualitative study. English for Specific Purposes, 25(3), 282-309.

[30] Lynch, T. (2014). Writing up qualitative research. English language teaching centre, University of Edinburgh. Retrieved: http://www.docs.hss.ed.ac.uk/iad/Postgraduate/PhD_researchers/Writing/O_Writing_Up_opening.pdf .

[31] Manchishi, P. C., Ndhlovu, D., \& Mwanza, S. D. (2015). Common mistakes committed and challenges faced in research proposal writing by University of Zambia postgraduate students. International Journal of Humanities Social Sciences and Education, 2(3), 126-138.

[32] Macnee, C. L., \& McCabe, S. (2008). Understanding nursing research: Using research in evidence-based practice. Lippincott Williams \& Wilkins.

[33] Morales, R.C. (2016). Discourse features of methodology sections of research articles in high-impact and non-high-impact applied linguistics journals. Asian Journal of English Language Studies

[34] Musa, N., Khamis, N., \& Zanariah, J. (2015). The structure of method section in Engineering research articles. Asian Social Science, 11(17), 74-82.

[35] Nguyen, T. T. L., \& Pramoolsook, I. (2015). A move analysis of method chapters by Vietnamese TESOL master's students. Research Scholar: An International Refereed e-Journal of Literary Explorations, 3(1), 14-28.

[36] Parodi, G. (2014). Genre organization in specialized discourse: Disciplinary variation across university textbooks. Discourse Studies, 16(1), 6587.

[37] Patton, M. Q. (1999). Enhancing the quality and credibility of qualitative analysis. Health services research, 34(5 Pt 2), 1189.

[38] Peacock, M. (2011). The structure of the methods section in research articles across eight disciplines. The Asian ESP Journal, 7(2), 97-123.

[39] Pho, P. D. (2008). Research article abstracts in applied linguistics and educational technology: A study of linguistic realizations of rhetorical structure and authorial stance. Discourse Studies, 10(2), 231-250. 
[40] Ruiying, Y., \& Allison, D. (2003). Research articles in applied linguistics: Moving from results to conclusions. English for specific purposes, 22(4), 365-385.

[41] Salager-Meyer, F. (1992). A text-type and move analysis study of verb tense and modality distribution in medical English abstracts. English for specific purposes, 11(2), 93-113.

[42] Samraj, B. (2002). Introductions in research articles: Variations across disciplines. English for specific purposes, 21(1), 1-17.

[43] Swales, J. (1990). Genre analysis: English in academic and research settings. Cambridge University Press.

[44] Swales, J., \& Feak, C. (2000) English in today's research world: A writing guide. Ann Arbor, MI: University of Michigan Press.

[45] Tobin, G. A., \& Begley, C. M. (2004). Methodological rigour within a qualitative framework. Journal of advanced nursing, 48(4), 388-396.

[46] Tseng, F. P. (2011). Analyses of move structure and verb tense of research article abstracts in applied linguistics journals. International journal of English linguistics, 1(2), 27.

[47] Tulud, D. (2016). Probes on the rhetorical moves of research methods in research Articles. Asian EFL Journal.

[48] Williams, I. (1999). Results section of medical research articles: Analysis of rhetorical categories for pedagogical purposes. English for Specific Purposes, 18(4), 347-366.

[49] Zhou, S., \& Sloan, W. D. (2009). Research methods in communications. Northport, AL: Vision Press. 